\title{
Androgens Protect against Apolipoprotein E4-Induced Cognitive Deficits
}

\author{
Jacob Raber, ${ }^{1,2}$ Gerold Bongers, ${ }^{1}$ Anthony LeFevour, ${ }^{1}$ Manuel Buttini, ${ }^{1}$ and Lennart Mucke ${ }^{1,2}$ \\ ${ }^{1}$ Gladstone Institute of Neurological Disease and ${ }^{2}$ Department of Neurology, University of California, San Francisco, \\ California 94141
}

\begin{abstract}
Compared with apolipoprotein (apo) E2 and E3, apoE4 increases the risk of Alzheimer's disease (AD), but it remains unknown how apoE4 affects neuronal function. ApoE4 interacts with female gender, further increasing the risk of $A D$ and decreasing treatment response. Female mice are also more susceptible to apoE4-induced impairments of spatial learning and memory than male mice. To assess the role of sex steroids in this process, we studied mice deficient in mouse apoE $\left(A p o e^{-/-}\right)$and expressing human apoE4 or apoE3 in the brain at comparable levels. Even brief periods of androgen treatment improved the memory deficits of female apoE4 mice. Female apoE3 mice had no memory deficits and did not benefit from the treatment. ApoE4 male mice, which performed normally in
\end{abstract}

Apolipoprotein (apo) E plays an important role in the metabolism and redistribution of lipoproteins and cholesterol (Mahley, 1988). It has been implicated in neural development, regeneration, neurite outgrowth, and neuroprotection, as well as in regulating the synthesis of glucocorticoids and sex hormones (Nathan et al., 1994; Gordon et al., 1995; Masliah et al., 1995; Poirier et al., 1995; Sun et al., 1998; Z hang et al., 1998; Buttini et al., 1999, 2000; Zerbinatti and Dyer, 1999; Raber et al., 2000a; Peskind et al., 2001; Zerbinatti et al., 2001). The three major human apoE isoforms (E2, E3, and E4) differ in their effect on Alzheimer's disease (AD). Compared with apoE2 and apoE3, apoE4 increases the risk of AD and, possibly, also of age-related cognitive decline in general (Corder et al., 1993, 1995; Roses, 1996; Farrer et al., 1997; Yaffe et al., 2000). ApoE4 interacts with female gender, further increasing the risk of $\mathrm{AD}$ and diminishing treatment responsivity in women (Reed et al., 1994; Farlow, 1997; Yaffe et al., 2000).

Understanding apoE-gender interactions in relation to cognitive decline is of fundamental interest and has potential implications for the treatment and prevention of AD. To assess these interactions, we studied female and male mice in which human apoE3 or apoE4 are expressed in the brain at comparable levels in the absence of mouse apoE (Raber et al., 1998, 2000b; Buttini et al., 1999, 2000). As demonstrated in these studies, apoE4

Received Dec. 3, 2001; revised Feb. 28, 2002; accepted March 29, 2002.

This work was supported by National Institutes of Health Grant AG11385, the Alzheimer's Association, and the John Douglas French Alzheimer's Foundation. We thank Dr. Rudolph Neri for hydroxyflutamide, Stephen Ordway and Gary Howard for editorial assistance, and Jack Hull and John Carroll for the preparation of graphics.

Correspondence should be addressed to Dr. Jacob Raber, Departments of Behavioral Neuroscience and Neurology, L470, Oregon Health and Science University, 3181 Southwest Sam Jackson Park Road, Portland, OR 97201. E-mail: raberj@ohsu.edu.

Copyright (ㄷ) 2002 Society for Neuroscience $\quad 0270-6474 / 02 / 225204-06 \$ 15.00 / 0$ a water-maze test at baseline, developed prominent deficits in spatial learning and memory after blockade of androgen receptors (ARs), whereas apoE3 male mice did not. Untreated apoE4 mice had significantly lower cytosolic AR levels in the neocortex than wild-type, $A p o e^{-/-}$, and apoE3 mice. Improved memory in androgen-treated female apoE4 mice was associated with increased cytosolic AR levels. Our findings suggest that apoE4 contributes to cognitive decline by reducing AR levels in the brain, and that stimulating AR-dependent pathways can reverse apoE4-induced cognitive deficits.

Key words: apoE; spatial learning and memory; novel object recognition; testosterone; dihydrotestosterone; androgen receptor; hydroxyflutamide expression impairs spatial learning and memory in female but not male apoE transgenic mice compared with $A p o e^{-/-}$mice and wild-type controls. In contrast, expression of apoE3 or the complete lack of apoE did not significantly affect spatial learning or memory compared with wild-type controls (Raber et al., 1998, 2000b).

Sex steroids cause sex differences in brain organization (Beatty, 1979) and also affect behaviors in adulthood (Joseph et al., 1978). Male rodents castrated at birth have learning curves in the water maze resembling those of females, and administration of testosterone to newborn female rodents produces learning curves resembling those of males (Joseph et al., 1978). Testosterone, but not $17 \beta$-estradiol, enhanced spatial memory in some studies (MacLusky et al., 1987; Janowsky et al., 1994); however, other studies reported enhanced spatial memory after estrogen replacement (Daniel et al., 1998; Gibbs, 1999). Because testosterone, but not dihydrotestosterone, can be converted to $17 \beta$-estradiol, comparing the effects of these androgens can help evaluate the relative contributions of androgen- versus estrogen-dependent pathways.

In the present study, we demonstrate that the genderdependent behavioral deficits induced by apoE4 affect not only spatial but also nonspatial learning and memory, that these effects are independent of whether apoE4 is produced in neurons or astrocytes, that apoE4 decreases cytosolic androgen receptor (AR) levels in the neocortex, that AR-dependent pathways protect male mice against apoE4-induced behavioral deficits, and that androgen treatment of female apoE4 mice reverses their behavioral deficits as well as their reduction in cortical AR levels.

\section{MATERIALS AND METHODS}

Mice. C57BL/6J mice were obtained from The Jackson Laboratory (Bar Harbor, ME). The generation and genotyping of neuron-specific enolase (NSE)-apoE mice have been described previously (Raber et al., 1998; Buttini et al., 1999). The NSE-apoE mice used in this study had been 
backcrossed onto the C57BL/6J Apoe $e^{-/-}$background for 15 generations. GFAP-apoE mice were generated by microinjecting GFAP-apoE fusion genes consisting of GFAP from C259 (Johnson et al., 1995) and apoE from NSE-apoE (Raber et al., 1998; Buttini et al., 1999) into C57BL/6J embryos. Offspring from GFAP-apoE transgenic founders were crossed for one generation with $\mathrm{B} 6 \mathrm{D} 2 \mathrm{~F}_{1}$ breeders and then for three generations onto the C57BL/6J Apoe ${ }^{-/-}$background. GFAP-apoE mice were compared with $A p o e^{-1-}$ littermate controls. The behavior of the latter Apoe $^{-1-}$ mice was indistinguishable from that of $A p o e^{-1-}$ mice that had been backcrossed onto the $\mathrm{C} 57 \mathrm{BL} / 6 \mathrm{~J}$ strain for $\geq 10$ generations (data not shown). To minimize the effects of social influences on behavior, all mice were housed singly starting 1 week before behavioral testing under conditions of constant temperature $\left(18^{\circ} \mathrm{C}\right)$ and light from 6:00 A.M. to 6:00 P.M. Although we did not monitor estrogen levels in this study, it is likely that all groups of female mice contained mice in different stages of the estrous cycle. All mice had access to food (PicoLab Rodent Diet 20, \#5053; PMI Nutrition International, St. Louis, MO) and water ad libitum. They were analyzed at 6-8 months of age.

Treatments and hormone measurements. SILASTIC capsules (inner diameter, $1.57 \mathrm{~mm}$; outer diameter, $3.18 \mathrm{~mm}$; Dow Corning, Midland, MI) were filled with testosterone or dihydrotestosterone (Sigma, St. Louis, MO); placebo capsules were empty. Under methoxyflurane or isoflurane anesthesia, the hair at the back of the neck of mice was cleaned with ethanol, a $0.5 \mathrm{~cm}$ incision was made, a hormone or placebo capsule was implanted subcutaneously, and the incision was closed with sutures. Plasma hormone levels were measured by radioimmunoassay (testosterone; ICN Biochemicals, Costa Mesa, CA) (dihydrotestosterone; Diagnostic Systems, Webster, TX) per the manufacturer's instructions. The AR antagonist hydroxyflutamide (a gift from Dr. Rudolph Neri, Schering-Plough Research Institute, Union, NJ) was dissolved in corn oil and injected subcutaneously once a day at $160 \mathrm{mg} / \mathrm{kg}$, starting $3 \mathrm{~d}$ before and continuing until the last day of behavioral testing. Controls were injected with corn oil alone. At the doses used here and in the presence of androgens, hydroxyflutamide acts as an AR antagonist; in the absence of androgen and at concentrations of $\geq 1 \mu \mathrm{M}$, it can act as an AR agonist (Tan et al., 1997).

Water-maze test. A pool (diameter, $122 \mathrm{~cm}$ ) was filled with opaque water $\left(24^{\circ} \mathrm{C}\right)$, and mice were trained to locate first a visible platform (days 1 and 2) and then a submerged hidden platform (days 3-5) in two daily sessions $3.5 \mathrm{hr}$ apart, each consisting of three $60 \mathrm{sec}$ trials (at $10 \mathrm{~min}$ intervals). Mice that failed to find the hidden platform within $60 \mathrm{sec}$ were put on it for $15 \mathrm{sec}$. For analysis of data, the pool was divided into four quadrants. During the visible platform training, the platform was moved to a different quadrant for each session. During the hidden platform training, the platform location was kept constant for each mouse (in the center of the target quadrant). The starting point at which the mouse was placed into the water was changed for each trial. Time to reach the platform (latency), path length, and swim speed were recorded with a Noldus Instruments EthoVision video tracking system (Noldus Information Technology, Sterling, VA) set to analyze two samples per second. Because there were no significant differences in average swim speeds between the different groups of mice during the visible platform sessions (data not shown), the time required to locate the platform (latency) was used as the main measure for analysis. A $60 \mathrm{sec}$ probe trial (platform removed) was performed $1 \mathrm{hr}$ after the last hidden-platform session.

Novel-object recognition. Novel-object recognition was used to evaluate nonspatial learning and memory (Rampon et al., 2000). On 3 consecutive days, the mice were habituated individually to an open field for $5 \mathrm{~min}$. For both the training and retention sessions, two objects were placed in the open field, and the animal was allowed to explore for $15 \mathrm{~min}$; before the retention test ( $24 \mathrm{hr}$ after the training session), one of the familiar objects was replaced by a novel object and the other familiar object was replaced by a replica. The time spent exploring each object during the training and retention sessions was recorded by an observer.

Cytosolic androgen receptor binding assay. For the determination of cytosolic AR binding, the method of McGinnis et al. (1983) was used, with slight modifications. Briefly, the entire neocortex and the hippocampal formation were dissected and homogenized separately with a glassTeflon homogenizer (the pestle was raised and lowered 20 times) in 4 and $1 \mathrm{ml}$ of TEDGM (10 mM Tris, $1.5 \mathrm{~mm}$ EDTA, $1 \mathrm{~mm}$ dithiothreitol, $10 \%$ glycerol, and $25 \mathrm{~mm}$ sodium molybdate), respectively. All steps were performed at $4^{\circ} \mathrm{C}$. The homogenates were centrifuged at $1000 \times g$ for 10 min with an IEC Centra (Needham Heights, MA) GB8R centrifuge. The supernatant was then centrifuged at $120,000 \times g$ for 30 min with a Beckman L8-70 Ultracentrifuge with a NVT65 rotor (Beckman Instru- ments, Fullerton, CA). Subsequently, $100 \mu \mathrm{l}$ of the cytosolic fraction was incubated with different concentrations of $\left[{ }^{3} \mathrm{H}\right] \mathrm{R} 1881(75.2 \mathrm{Ci} / \mathrm{mmol}$; NEN, Boston, MA) and $10 \mu \mathrm{M}$ triamcinolone acetonide in a total volume of $250 \mu \mathrm{l}$ of TEDGM. Nonspecific binding was determined in separate incubation tubes containing the radioligand in the presence of a 100 -fold excess of DHT. After overnight incubation, $100 \mu \mathrm{l}$ of each sample was passed through a Sephadex LH-20 column (Sigma) to separate bound from free $\left[{ }^{3} \mathrm{H}\right] \mathrm{R} 1881$. Columns were prepared with LH-20 that had been incubated in TEGM (10 mM Tris, $1.5 \mathrm{~mm}$ EDTA, $10 \%$ glycerol, and 25 mu sodium molybdate) for at least $24 \mathrm{hr}$ before use. The swollen LH-20 was poured into blue pipette tips (Rainin Pipetman, Woburn, MA) fitted with $4 \mathrm{~mm}$ glass beads at the bottom. The columns were washed with 200 $\mu \mathrm{l}$ of TEDGM $15 \mathrm{~min}$ before use. Application of the sample was followed by $100 \mu \mathrm{l}$ of TEDGM, and $15 \mathrm{~min}$ later by $200 \mu \mathrm{l}$ of TEGM. The samples were eluted with $200 \mu \mathrm{l}$ of TEGM, collected in scintillation vials, mixed with $7 \mathrm{ml}$ of Ecoscint $\mathrm{H}$ (National Diagnostics, Atlanta, GA), and counted in a Beckman Coulter LS-6500 Multi-Purpose Scintillation counter (Beckman Instruments). Results were expressed as femtomoles of $\left[{ }^{3} \mathrm{H}\right] \mathrm{R} 1881$ bound per milligram of protein. The $B_{\max }$ was determined with GraphPad (San Diego, CA) Prism software (version 3.0 for Macintosh), using a single curve-fit analysis. The protein concentrations were determined by the method of Bradford (1976).

Statistical analysis. Statistical analyses were performed with StatView 5.0 (SAS Institute, Cary, NC). Differences among means were evaluated by ANOVA, followed by the Tukey-Kramer post hoc test if indicated. Learning curves were compared by repeated-measures ANOVA using contrasts to assess differences between specific groups of mice. For all analyses, the null hypothesis was rejected at the 0.05 level.

\section{RESULTS}

\section{Androgens improve deficits in spatial learning and memory in apolipoprotein E4 female mice}

To test whether androgens can ameliorate cognitive deficits in female apoE4 mice, 6-month-old female NSE-apoE mice were anesthetized, and SILASTIC capsules filled with androgens (testosterone or dihydrotestosterone) were implanted subcutaneously. Controls received placebo capsules. Testosterone and dihydrotestosterone exert androgenic effects by interacting with ARs (Couse and Korach, 1998). In contrast to testosterone, dihydrotestosterone cannot be converted to $17 \beta$-estradiol by aromatase.

Eight days after implantation of the capsules, the mice were tested in the water maze. They were first trained to locate a visible platform (cued training) and then to locate a hidden platform (acquisition). Subsequently, the hidden platform was removed (probe trial) to measure the retention of spatial memory. Testosterone improved the spatial learning and memory in female apoE4 mice (Fig. $1 A, B$ ) but not in female apoE3 mice (Fig. $1 C, D)$. This was already obvious in the second and third trials of the first hidden-platform session (Fig. 1E,F). The apparent deleterious effects of testosterone on the water-maze performance of female apoE3 mice in trial 2 indicate that testosterone does not nonspecifically improve water-maze performance in apoE mice and that it benefits only apoE4 but not apoE3 females, underlining the importance of genetic factors in the response to drug treatments for cognitive disorders.

Although dihydrotestosterone also had beneficial effects on memory retention, it was less effective than testosterone (Fig. $1 B)$. Therefore, it is possible that the testosterone effects in female apoE4 mice were partially mediated by $17 \beta$-estradiol. A potential role for $17 \beta$-estradiol is also supported by the effect of testosterone, but not dihydrotestosterone, on the learning curve and the apparent crossover of the learning curve of dihydrotestosterone-treated compared with placebo-treated apoE4 mice (Fig. 1A). However, we cannot exclude the possibility that more prolonged treatment with dihydrotestosterone would result in further improvements. 

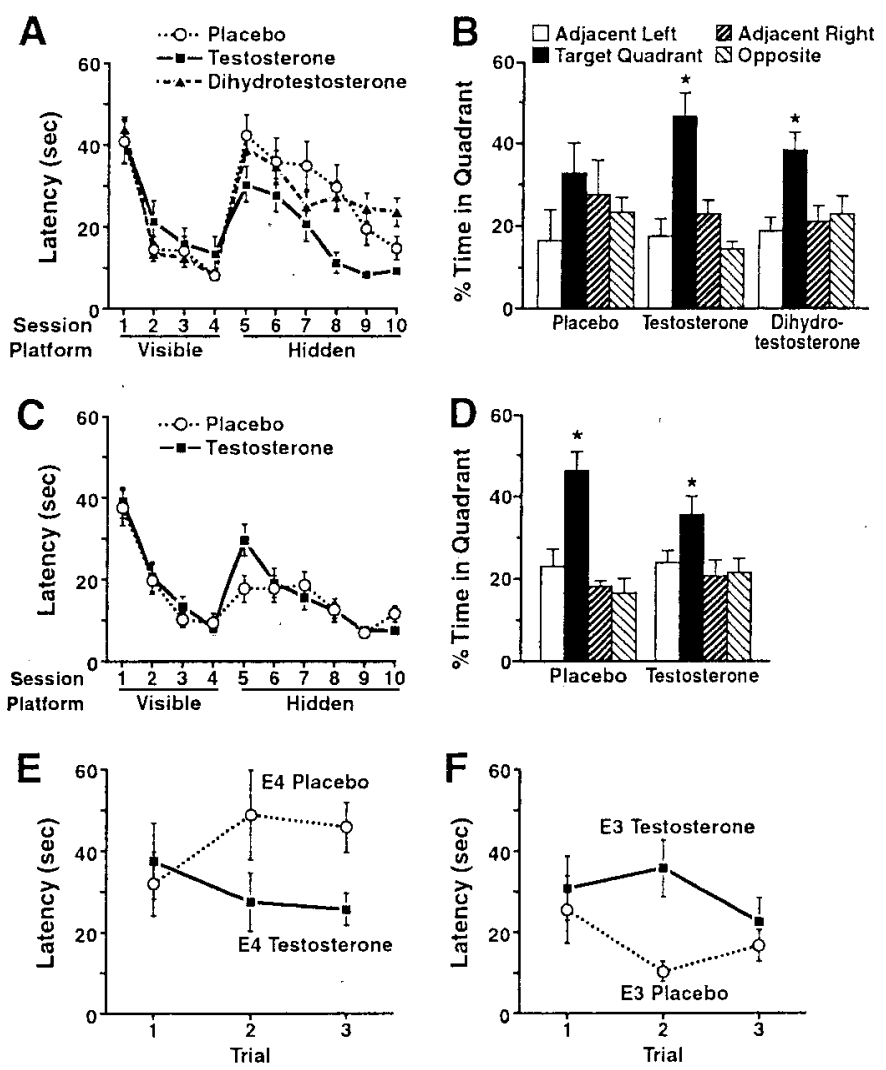

Figure 1. ApoE4-induced deficits in spatial learning and memory can be improved by stimulating ARs. Six-month-old female NSE-apoE4 and NSE-apoE3 mice were tested in the water maze beginning $8 \mathrm{~d}$ after the subcutaneous implantation of testosterone, dihydrotestosterone, or placebo capsules ( $n=5-11$ mice per genotype and treatment). After the behavioral testing, plasma hormone levels were determined by radioimmunoassay to ensure the effectiveness of the implants (see Results). $A$, Testosterone improved spatial learning in female apoE4 mice. Although all three groups learned to locate the hidden platform, there was a significant difference between the learning curves of testosterone- and placebo-treated mice during the hidden-platform sessions $(p<0.05$; repeated-measures ANOVA). $B$, In the probe trial (platform removed), both testosterone- and dihydrotestosterone-treated apoE4 mice, but not placebo-treated apoE4 mice, spent significantly more time searching in the target quadrant than in any of the other quadrants $\left({ }^{*} p<0.05\right.$; Tukey-Kramer test). However, the dihydrotestosterone effect was relatively weak. Although the ratio of mice spending $\geq 35 \%$ versus $<35 \%$ in the target quadrant was higher after testosterone (5:0) than after placebo (1:4) treatment $\left(p<0.01 ; \chi^{2}\right.$ test), it did not differ significantly from placebo after dihydrotestosterone treatment $\left(5: 4 ; p=0.2 ; \chi^{2}\right.$ test $)$. Learning curves calculated from distance moved were similar to those calculated from latencies (data not shown). $C, D$, Testosterone did not improve spatial learning and memory in female apoE3 mice. ${ }^{*} p<0.05$ versus any other quadrant (Tukey-Kramer test). $E, F$, Trials 1-3 of the first hiddenplatform session. Latency values for each session $(A, C)$ represent the averages from three consecutive trials. Comparison of latencies in each of the first three hidden-platform trials by ANOVA revealed a significant interaction between treatment and genotype during trials $2(p=0.002)$ and $3(p=0.027)$ but not trial $1(p=0.95)$. Comparison of the four learning curves by repeated-measures ANOVA also identified a significant interaction between treatment and genotype $(p=0.028)$. Moreover, the effect of genotype was significant only in the placebo-treated groups $(p=0.002)$ but not in the testosterone-treated groups $(p=0.93)$.

\section{Blockade of androgen receptors impairs spatial learning and memory in male apolipoprotein E4 mice but not in male apolipoprotein E3 mice}

We subsequently tested whether AR-dependent pathways protect male NSE-apoE mice against apoE4-induced cognitive deficits.
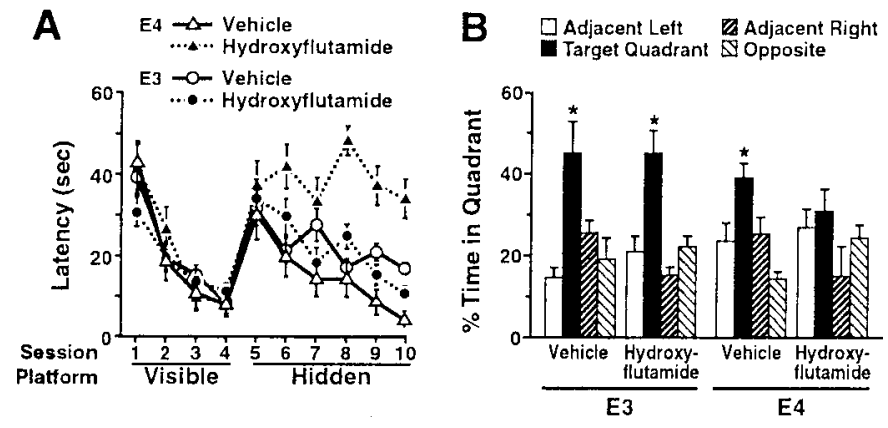

Figure 2. Blockade of ARs impaired spatial learning and memory in male apoE4 but not apoE3 mice. Six-month-old male NSE-apoE4 and NSE-apoE3 mice ( $n=6-7$ mice per genotype and treatment) were tested in the water maze during AR blockade with hydroxyflutamide (see Materials and Methods). A, Hydroxyflutamide impaired learning in the hidden-platform sessions in apoE4 mice $(p<0.05$ vs vehicle-treated apoE4 mice; repeated-measures ANOVA) but not in apoE3 mice. $B$, Hydroxyflutamide impaired retention of spatial memory in apoE4 but not apoE3 mice. ${ }^{*} p<0.05$ versus any other quadrant (Tukey-Kramer test).

Six-month-old mice received daily subcutaneous injections of the AR antagonist hydroxyflutamide (Malgor et al., 1998), starting $3 \mathrm{~d}$ before testing in the water maze. In contrast to female apoE4 mice, untreated (Raber et al., 1998) or placebo-treated (Fig. $2 A, B)$ male apoE4 mice and apoE3 mice showed no deficits in this test. AR blockade induced striking impairments in spatial learning and memory in male apoE4 but not apoE3 mice (Fig. $2 A, B)$.

\section{Plasma testosterone levels depend on gender but not on apolipoprotein $\mathbf{E}$ isoform expressed in the brain}

Plasma testosterone levels (in nanograms per milliliter) did not differ significantly in untreated 6- to 8-month-old male apoE4 [2.64 $\pm 0.73($ mean $\pm \mathrm{SD}), n=19]$, apoE3 (4.12 $\pm 1.21 ; n=10)$, and $A p o e^{-1-}(2.88 \pm 0.92 ; n=18)$ mice. This indicates that isoform-specific effects of apoE on plasma testosterone levels did not contribute to the differential effects of AR blockade in male apoE3 and apoE4 mice. Plasma testosterone levels in most of the untreated female apoE3, apoE4, and $A p o e^{-1-}$ mice were below the detection threshold of our assay. The physiologically higher levels of endogenous testosterone in males may provide a relative protection against apoE4-induced cognitive deficits.

\section{Novel-object recognition}

We then examined whether the effects of AR-dependent pathways on apoE4-induced cognitive deficits are restricted to spatial learning and memory. This is an important question, because females may in general be more susceptible to spatial memory impairments than males. For example, in rodents with medial frontal cortical lesions, males were less impaired than females in mazes that required the use of multiple visuospatial cues for a successful solution (Kolb and Cioe, 1996).

To determine whether apoE4 also exerts gender-dependent detrimental effects on nonspatial learning and memory, we assessed 6-month-old male and female apoE4, apoE3, wild-type, and $A p o e^{-/-}$mice in a novel-object recognition test (Rampon et al., 2000). During the training session, mice were allowed to explore an open field containing two objects for $15 \mathrm{~min}$. For the retention session ( $24 \mathrm{hr}$ later), they were placed for $15 \mathrm{~min}$ into the same open field, in which one of the familiar objects had been replaced with a novel object and the other familiar object had been replaced with an exact replica. The percentage of time the 
mice spent exploring the novel versus the familiar object relative to the total amount of time they explored either object in the retention session was used as a measure of object-recognition memory.

In the training session, all groups of mice spent a comparable amount of time exploring each object (data not shown). In the retention session, only female apoE4 mice showed significant deficits, whereas male apoE4 mice and male or female apoE3, wild-type, and $A p o e^{-1-}$ mice had intact object-recognition memory (Fig. $3 A, B)$. Female apoE4 mice spent a significantly smaller proportion of time exploring the novel object than female apoE3 mice or wild-type controls ( $p<0.05$; Tukey-Kramer test).

Deficits in object-recognition memory were also identified in female mice of an independent transgenic line in which expression of apoE4 was targeted to astrocytes with the GFAP promoter (Fig. 3C). Human apoE mRNA levels in the brains of GFAPapoE4 mice (data not shown) were similar to those in NSE-apoE mice (Raber et al., 1998; Buttini et al., 1999).

\section{Apolipoprotein E4 decreases cytosolic androgen receptor levels}

How might apoE4 affect AR-dependent pathways? As a first step toward answering this question, we used an AR binding assay to determine cytosolic AR levels in the neocortex and hippocampus of our apoE transgenic mice. Female and male apoE4 mice had lower cytosolic AR levels in the neocortex than apoE3, Apoe ${ }^{-1-}$, or wild-type mice (Fig. 4A). Cytosolic AR levels in the hippocampus of apoE3 and apoE4 mice were not significantly different (data not shown).

Why do only female apoE4 mice show deficits in learning and memory although female and male apoE4 mice have comparable decreases in cortical AR levels (Fig. 4A)? Cognitive performance likely depends on a critical balance between plasma androgen levels and cytosolic AR levels in the brain. Although the higher endogenous plasma testosterone levels in male apoE4 mice may provide relative protection, our AR-blocking experiment (Fig. $2 A, B)$ suggests that they are not high enough to compensate fully for the AR-lowering effect of apoE4.

Consistent with this notion, plasma testosterone levels in testosterone-treated female apoE4 mice $(5.61 \pm 0.74 ; n=6)$ were roughly twice as high as those in untreated male apoE4 mice $(2.64 \pm 0.73 ; n=19)$. Testosterone and dihydrotestosterone treatments increased AR levels in the neocortex of female apoE4 mice (Fig. $3 B-D$ ). The $B_{\max }$ values (in femtomoles per milligram of protein) were $3.19 \pm 0.39$ for placebo $(n=3$ mice $), 6.12 \pm 0.45$ for testosterone $(n=4)$, and $5.92 \pm 0.54$ for dihydrotestosterone $(n=6)$ treatments.

\section{DISCUSSION}

This study shows that androgens and AR-dependent pathways protect against the detrimental effects of apoE4 on learning and memory. Androgen treatment improved memory deficits in female apoE4 mice. ApoE4 male mice, which performed normally in a water-maze test at baseline, developed prominent deficits in spatial learning and memory after AR blockade, whereas apoE3 male mice did not. ApoE4 expression in mice resulted in significantly reduced cytosolic AR levels in the neocortex and memory improvements in androgen-treated female apoE4 mice were associated with increased cytosolic AR levels.

The detrimental effects of apoE4 on novel-object recognition in female but not male mice demonstrate that apoE4 induces gender-dependent deficits not only in spatial but also in nonspa-

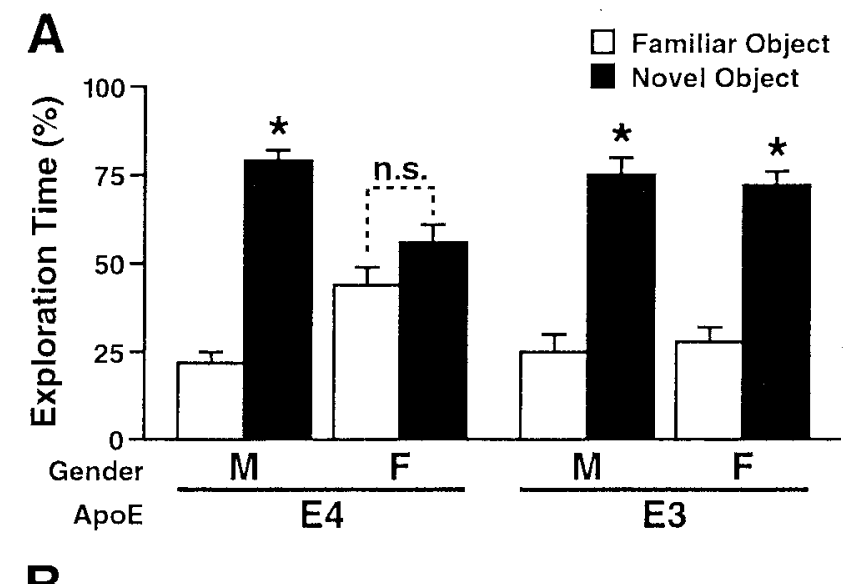

B
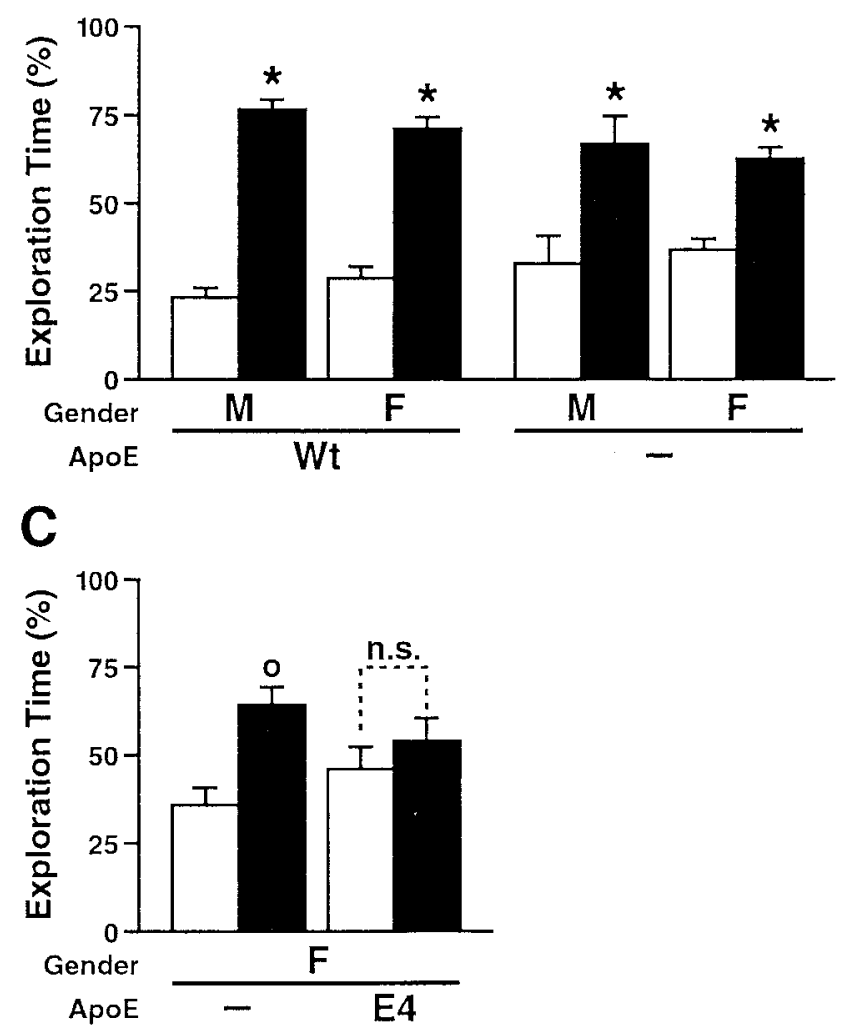

Figure 3. ApoE4 impairs object-recognition memory in female mice. Novel-object recognition was tested in untreated 6-month-old male $(M)$ and female $(F)$ mice. The results shown are from the memory-retention session. $A$, NSE-apoE4 (11 males, 7 females) and NSE-apoE3 (4 males, 7 females) mice. $B$, Wild-type $(W t)$ (11 males, 6 females) and $A p o e^{-1-}(7$ males, 13 females) mice. C, Apoe ${ }^{-1-}$ (6 females) and GFAP-apoE4 (6 females) mice. Most mice showed normal object-recognition memory. Only female mice that expressed apoE4 in neurons $(A)$ or astrocytes $(C)$ failed to spend significantly more time with the novel than with the familiar object. ${ }^{\circ} p<0.05 ;{ }^{*} p<0.01$ versus time exploring the familiar object (Tukey-Kramer test); n.s., not significant.

tial learning and memory. The resistance of male apoE4 mice to deficits in object-recognition memory supports our conclusion that AR-dependent pathways protect against apoE4-induced cognitive impairments. The impairments in object-recognition memory in female apoE4 mice and the absence of such impairments in female mice that express no apoE at all are consistent with a pathogenic gain of function of apoE4 (Raber et al., 1998; Buttini et al., 1999, 2000). 
A
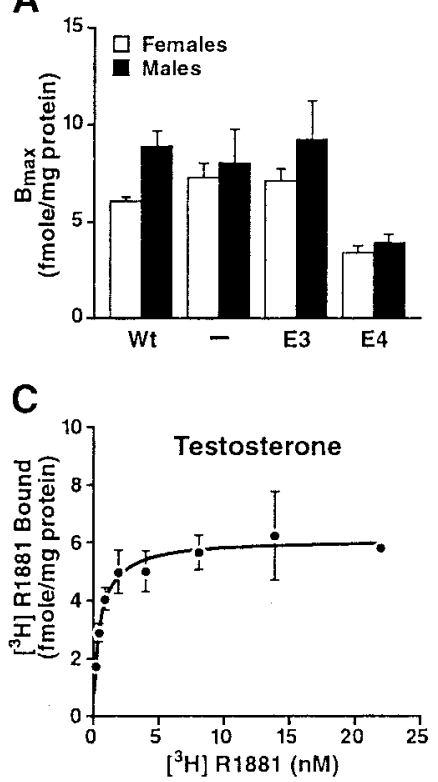

B

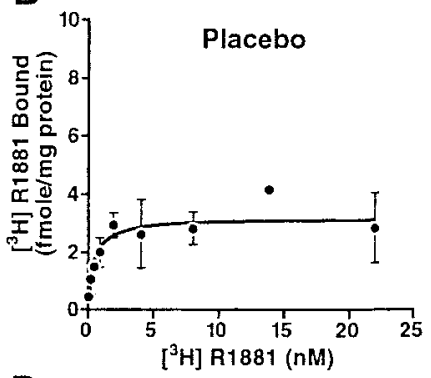

D

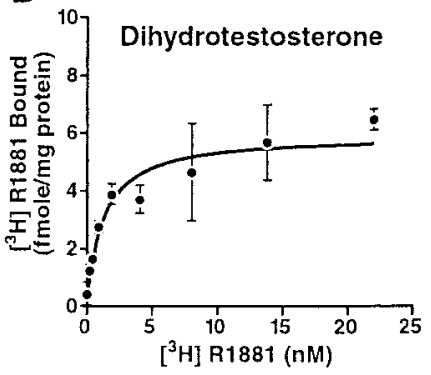

Figure 4. Cytosolic AR levels in the neocortex and response to androgen treatment. Total cytosolic AR levels were determined from AR saturation curves using a single curve-fit analysis. Results are expressed as femtomoles of $\left[{ }^{3} \mathrm{H}\right] \mathrm{R} 1881$ bound per milligram of protein. There were no differences in $K_{\mathrm{d}}$ among the groups (data not shown). $A$, Untreated male and female NSE-apoE4 mice had lower cytosolic AR levels than untreated NSE-apoE3, Apoe $e^{-/-}$, and wild-type $(W t)$ mice $(n=3-7$ mice per gender and genotype). $B-D$, Effect of placebo $(B)$, testosterone $(C)$, and dihydrotestosterone $(D)$ on AR saturation curves in female NSE-apoE4 mice $(n=3-6$ mice per treatment).

Deficits in spatial and nonspatial learning and memory were identified in female $A_{p o e^{-/-}}$mice that express apoE4 in neurons or astrocytes (Fig. 3), suggesting that apoE4-induced cognitive deficits are independent of the cellular source of apoE and likely involve secreted forms of apoE4.

Female and male apoE4 mice had reduced cytosolic AR levels in the neocortex but not in the hippocampus. Because pathological alterations involving the cortex, but not the hippocampus, can impair spatial and nonspatial learning and memory (Kesner et al., 1993; Aggleton et al., 1997; Ennaceur and Aggleton, 1997; Rogers and Hunter, 1997; Eijkenboom et al., 2000), it is likely that the apoE4-dependent decreases in cortical AR levels contributed to the development of behavioral deficits in female apoE4 mice. The improvement of behavioral deficits in female apoE4 mice after AR stimulation and the development of behavioral deficits in male apoE4 mice after AR blockade suggest that male apoE4 mice might be less susceptible to apoE4-induced AR reductions because of their higher circulating levels of endogenous androgens.

Testosterone and dihydrotestosterone treatments increased AR levels in the neocortex of female apoE4 mice to levels comparable to those in female and male wild-type, $\mathrm{Apoe}^{-/-}$, and apoE3 mice. Although the precise mechanisms by which apoE4 reduces AR levels in the brain remain to be determined, the above response is in line with the positive regulation of ARs by androgens in wild-type brains (Lu et al., 1998, 1999), suggesting that the apoE4-dependent reduction in AR levels does not preclude responsivity of ARs to androgen treatment.

It is estimated that $\sim 60 \%$ of people with $\mathrm{AD}$ have at least one $A P O E \in 4$ allele (Farrer et al., 1997), which implies that a substantial proportion of patients with AD could be affected by the

adverse effects of apoE4. Although species differences and the multifactorial causes of $\mathrm{AD}$ make it impossible to extrapolate directly from transgenic mice expressing human apoE isoforms to humans with $\mathrm{AD}$, a number of studies suggest that our findings have clinical relevance. In most studies, estrogen treatment was unable to slow the progression of AD (Ohkura et al., 1995; Henderson et al., 1996). Although some studies suggested that estrogen may delay or prevent the onset of AD (Benson, 1999; Sano, 2000), it had no beneficial effect on cognitive function in elderly women who carried the $A P O E \in 4$ allele (Yaffe et al., 2000). Furthermore, testosterone but not estrogen levels in serum correlated positively with cognitive performance in older women (Barrett-Connor and Goodman-Gruen, 1999), and testosterone therapy improved cognition in women rendered menopausal by surgery (Sherwin, 1988).

Together with the age-related decline in plasma testosterone levels in men and women (Vermeulen et al., 1999; Vermeulen, 2000; Janowsky et al., 2000), the AR-lowering effect of apoE4 could contribute to the increased susceptibility of human $A P O E$ $\epsilon 4$ carriers to $\mathrm{AD}$ and related cognitive decline. The finding that even brief treatment with testosterone significantly improved learning and memory in adult female apoE4 mice is encouraging. Increased efforts are warranted to test the efficacy of androgens or androgen derivatives in humans and to investigate their modes of action in related animal models.

\section{REFERENCES}

Aggleton JP, Keen S, Warburton EC, Bussey TJ (1997) Extensive cytotoxic lesions involving both the rhinal cortices and area TE impair recognition but spare spatial alternation in the rat. Brain Res Bull 43:279-287.

Barrett-Connor E, Goodman-Gruen D (1999) Cognitive function and endogenous sex hormones in older women. J Am Geriatr Soc 47:1289-1293.

Beatty WW (1979) Gonadal hormones and sex differences in nonreproductive behaviors in rodents: organizational and activational influences. Horm Behav 12:112-163.

Benson S (1999) Hormone replacement therapy and Alzheimer's disease: an update on the issues. Health Care Women Int 20:619-638.

Bradford MM (1976) A rapid and sensitive method for the quantitation of microgram quantities of protein utilizing the principle of protein-dye binding. Anal Biochem 72:248-254.

Buttini M, Orth M, Bellosta S, Akeefe H, Pitas RE, Wyss-Coray T, Mucke L, Mahley RW (1999) Expression of human apolipoprotein E3 or E4 in the brains of $A p o e^{-/-}$mice: isoform-specific effects on neurodegeneration. J Neurosci 19:4867-4880.

Buttini M, Akeefe H, Lin C, Mahley RW, Pitas RE, Wyss-Coray T, Mucke L (2000) Dominant negative effects of apolipoprotein E4 revealed in transgenic models of neurodegenerative disease. Neuroscience 97:207-210.

Corder EH, Saunders AM, Strittmatter WJ, Schmechel DE, Gaskell PC, Small GW, Roses AD, Haines JL, Pericak-Vance MA (1993) Gene dose of apolipoprotein E type 4 allele and the risk of Alzheimer's disease in late onset families. Science 261:921-923.

Corder EH, Saunders AM, Strittmatter WJ, Schmechel DE, Gaskell PCJ, Roses AD, Pericak-Vance MA, Small GW, Haines JL (1995) The apolipoprotein E $\epsilon 4$ allele and sex-specific risk of Alzheimer's disease. JAMA 273:373-374.

Couse JF, Korach KS (1998) Exploring the role of sex steroids through studies of receptor deficient mice. J Mol Med 76:497-511.

Daniel JM, Fader AJ, Spencer AL, Dohanich GP (1998) Estrogen enhances performance of female rats during acquisition of a radial arm maze. Horm Behav 32:217-225.

Eijkenboom M, Blokland A, Staay FJVD (2000) Modelling cognitive dysfunctions with bilateral injections of ibotenic acid into the rat entorhinal cortex. Neuroscience 101:27-39.

Ennaceur A, Aggleton JP (1997) The effects of neurotoxic lesions of the perirhinal cortex combined to fornix transection on object recognition memory in the rat. Behav Brain Res 88:181-193.

Farlow MR (1997) Alzheimer's disease: clinical implications of the apolipoprotein E genotype. Neurology 48:S30-S34.

Farrer LA, Cupples LA, Haines JL, Hyman B, Kukull WA, Mayeux R, Myers RH, Pericak-Vance MA, Risch N, van Duijn CM (1997) Ef- 
fects of age, sex, and ethnicity on the association between apolipoprotein E genotype and Alzheimer disease: a meta-analysis. JAMA 278:1349-1356.

Gibbs RB (1999) Estrogen replacement enhances acquisition of a spatial memory task and reduces deficits associated with hippocampal muscarinic receptor inhibition. Horm Behav 36:222-233.

Gordon I, Grauer E, Genis I, Sehayek E, Michaelson DM (1995) Memory deficits and cholinergic impairments in apolipoprotein E-deficient mice. Neurosci Lett 199:1-4.

Henderson VW, Watt L, Buckwalter JG (1996) Cognitive skills associated with estrogen replacement in women with Alzheimer's disease. Psychoneuroendocrinology 21:421-430.

Janowsky JS, Oviatt SK, Orwoll ES (1994) Testosterone influences spatial cognition in older men. Behav Neurosci 108:325-332.

Janowsky JS, Chavez B, Orwoll E (2000) Sex steroids modify working memory. J Cogn Neurosci 12:407-414.

Johnson WB, Ruppe MD, Rockenstein EM, Price J, Sarthy VP, Verderber LC, Mucke L (1995) Indicator expression directed by regulatory sequences of the glial fibrillary acidic protein (GFAP) gene: in vivo comparison of distinct GFAP-lacZ transgenes. Glia 13:174-184.

Joseph R, Hess S, Birecree E (1978) Effects of hormone manipulations and exploration on sex differences in maze learning. Behav Biol 24:364-377.

Kesner RP, Bolland BL, Dakis M (1993) Memory for spatial locations, motor responses, and objects: triple dissociation among the hippocampus, caudate nucleus, and extrastriate visual cortex. Exp Brain Res 93:462-470.

Kolb B, Cioe J (1996) Sex-related differences in cortical function after medial frontal lesions in rats. Behav Neurosci 110:1271-1281.

Lu S, Simon NG, Wang Y, Hu S (1999) Neural androgen receptor regulation: effects of androgen and antiandrogen. J Neurobiol 41:505-512.

Lu SF, McKenna SE, Cologer-Clifford A, Nau EA, Simon NG (1998) Androgen receptor in mouse brain: sex differences and similarities in autoregulation. Endocrinology 139:1594-1601.

MacLusky NJ, Clark AS, Naftolin F, Goldman-Rakic PS (1987) Estrogen formation in the mammalian brain: possible role of aromatase in sexual differentiation of the hippocampus and neocortex. Steroids 50:459-474.

Mahley RW (1988) Apolipoprotein E: cholesterol transport protein with expanding role in cell biology. Science 240:622-630.

Malgor LA, Valsecia M, Verges E, De Markowsky EE (1998) Blockade of the in vitro effects of testosterone and erythropoietin on $\mathrm{Cfu}-\mathrm{E}$ and Bfu-E proliferation by pretreatment of the donor rats with cyproterone and flutamide. Acta Physiol Pharmacol Ther Latinoam 48:99-105.

Masliah E, Mallory M, Ge N, Alford M, Veinbergs I, Roses AD (1995) Neurodegeneration in the central nervous system of apoE-deficient mice. Exp Neurol 136:107-122.

McGinnis MY, Davis PG, Meaney MJ, Singer M, McEwen BS (1983) In vitro measurement of cytosol and cell nuclear androgen receptors in male rat brain and pituitary. Brain Res 275:75-82.

Nathan BP, Bellosta S, Sanan DA, Weisgraber KH, Mahley RW, Pitas RE (1994) Differential effects of apolipoproteins E3 and E4 on neuronal growth in vitro. Science 264:850-852.

Ohkura T, Isse K, Akazawa K, Hamamoto M, Yaoi Y, Hagino N (1995) Long-term estrogen replacement therapy in female patients with dementia of the Alzheimer's type: 7 case reports. Dementia 6:99-107.

Peskind ER, Wilkinson CW, Petrie EC, Schellenberg GD, Raskind MA (2001) Increased CSF cortisol in AD is a function of APOE genotype. Neurology 56:1094-1098.
Poirier J, Minnich A, Davignon J (1995) Apolipoprotein E, synaptic plasticity and Alzheimer's disease. Ann Med 27:663-670.

Raber J, Wong D, Buttini M, Orth M, Bellosta S, Pitas RE, Mahley RW, Mucke L (1998) Isoform-specific effects of human apolipoprotein E on brain function revealed in $A p o E$ knockout mice: increased susceptibility of females. Proc Natl Acad Sci USA 95:10914-10919.

Raber J, Akana SF, Bhatnagar S, Dallman MF, Wong D, Mucke L (2000a) Hypothalamic-pituitary-adrenal dysfunction in Apoe ${ }^{-1-}$ mice: possible role in behavioral and metabolic alterations. J Neurosci 20:2064-2071.

Raber J, Wong D, Yu G-Q, Buttini M, Mahley RW, Pitas RE, Mucke L (2000b) Alzheimer's disease: apolipoprotein $\mathrm{E}$ and cognitive performance. Nature 404:352-354.

Rampon C, Tang YP, Goodhouse J, Shimizu E, Kyin M, Tsien JZ (2000) Enrichment induces structural changes and recovery from nonspatial memory deficits in CA1 NMDAR1-knockout mice. Nat Neurosci $3: 238-244$.

Reed T, Carmelli D, Swan GE, Breitner JC, Welsh KA, Jarvik G, Deeb S, Auwerx J (1994) Lower cognitive performance in normal older adult male twins carrying the apolipoprotein E $\epsilon 4$ allele. Arch Neurol 51:1189-1192.

Rogers DC, Hunter AJ (1997) Photothrombotic lesions of the rat cortex impair acquisition of the water maze. Pharmacol Biochem Behav 56:747-754.

Roses AD (1996) Apolipoprotein E and Alzheimer's disease: a rapidly expanding field with medical and epidemiological consequences. Ann NY Acad Sci 802:50-57.

Sano M (2000) Understanding the role of estrogen on cognition and dementia. J Neural Transm Suppl 59:223-229.

Sherwin BB (1988) Estrogen and/or androgen replacement therapy and cognitive functioning in surgically menopausal women. Psychoneuroendocrinology 13:345-357.

Sun YL, Wu S, Bu GJ, Onifade MK, Patel SN, LaDu MJ, Fagan AM, Holtzman DM (1998) Glial fibrillary acidic protein-apolipoprotein E (apoE) transgenic mice: astrocyte-specific expression and differing biological effects of astrocyte-secreted apoE3 and apoE4 lipoproteins. J Neurosci 18:3261-3272.

Tan J, Sharief Y, Hamil KG, Gregory CW, Zang D-Y, Sar M, Gumerlock PH, deVere White RW, Pretlov TG, Harris SE, Wilson EM, Mohler JL, French FS (1997) Dehydroepiandrosterone activates mutant androgen receptors expressed in the androgen-dependent human prostate cancer xenograft CWR22 and LNCaP cells. Mol Endocrinol 11:450-459.

Vermeulen A (2000) Andropause. Maturitas 34:5-15.

Vermeulen A, Goemaere S, Kaufman JM (1999) Testosterone, body composition and aging. J Endocrinol Invest 22:110-116.

Yaffe K, Haan M, Byers A, Tangen C, Kuller L (2000) Estrogen use, APOE, and cognitive decline: evidence of gene-environment interaction. Neurology 54:1949-1953.

Zerbinatti CV, Dyer CA (1999) Apolipoprotein E peptide stimulation of rat ovarian theca cell androgen synthesis is mediated by members of the low density receptor superfamily. Biol Reprod 61:665-672.

Zerbinatti CV, Mayer LP, Audet RG, Dyer CA (2001) Apolipoprotein $\mathrm{E}$ is a putative autocrine regulator of the rat ovarian theca cell compartment. Biol Reprod 64:1080-1089.

Zhang G, Curtiss LK, Wade RL, Dyer CA (1998) An apolipoprotein E synthetic peptide selectively modulates the transcription of the gene for rat ovarian theca and interstitial cell P450 17-alpha-hydroxylase, C17-20 lyase. J Lipid Res 39:2406-2414. 